\title{
An Eco-Translatological Study on Shuhui Yang and Yunqin Yang's Translation of Sanyan
}

\author{
Lin Tian \\ School of Foreign Languages, Sichuan University of Arts and Science, Dazhou, China \\ Email: tianlin1984@126.com
}

How to cite this paper: Lin, T. (2018) An Eco-Translatological Study on Shuhui Yang and Yunqin Yang's Translation of Sanyan. Open Access Library Journal, 5: e4825. https://doi.org/10.4236/oalib.1104825

Received: August 3, 2018

Accepted: August 19, 2018

Published: August 22, 2018

Copyright (๑) 2018 by author and Open Access Library Inc.

This work is licensed under the Creative Commons Attribution International License (CC BY 4.0).

http://creativecommons.org/licenses/by/4.0/

\section{(c) (i) Open Access}

\begin{abstract}
Eco-translatology emphasizes the harmony and unity of various components in the translational eco-environment, and holds that translation is not a static but a dynamic activity. Thus, it's not one specific translation strategy or technique that plays a decisive role in the translation process, but the flexible selection of the translator who is at the central position in the eco-environment. Within this framework, the present paper explores Shuhui Yang and Yunqin Yang's translation of Sanyan, finding that the two translators have well balanced and coordinated the relationship among the writer, the translator and the readers. They have not only achieved loyalty to the source text and writer in style by providing a panoramic view of huaben through translation, but also catered for the expectations of readers by applying different techniques such as transplantation and endnotes. It can be seen that the translator's centeredness has been well reflected in the translation activity.
\end{abstract}

\section{Subject Areas}

Education, Literature

\section{Keywords}

Sanyan, Eco-Translatology, Translation, Shuhui Yang and Yunqin Yang

\section{Introduction}

Sanyan, a milestone in the development of vernacular short stories, was compiled by Feng Menglong, a famous writer in the Ming Dynasty (1368-1644) who has produced many works which can even be "'piled up to reach his own height' (zhuzuodengshen), a phrase traditionally used by critics to praise exceptionally productive writer" [1]. Representing Feng's greatest achievement in his literary life, Sanyan is composed of three vernacular short-story collections with 40 sto- 
ries in each, which are Gujinxiaoshuo, Jingshitongyan and Xingshihengyan. It portrays "a vivid panoramic view of the bustling world of imperial China before the end of Ming" [1], where the daily lives of people of various class are described and depicted, such as emperors, merchants, ordinary men and women, prostitutes and so on. "Since some scholars credit FengMenglong with the creation of "popular literature"' [2], his collections of Sanyan are believed to have "set new standards for breadth of theme and motif, detail in characterization, and cleverness in the creation of dialogue" [2]. Therefore, these short novel collections are selected as the research objects. Sanyan, as a masterpiece of vernacular novels, has exerted great influence on the development of literature and also attracted the attention of the translational field. However, by the end of the 20th century, all the existing translations of Sanyan were scattered and unsystematic, until Shuhui Yang and Yunqin Yang produced the most complete translation at the turn of the century, including the translation of preface, interlineal comments and the opening parts, etc. Just as stated by Robert E. Hegel, "Shuhui and Yunqin Yang have provided a rare treat for English readers: an unparalleled view of the art of short fiction from seventeenth-century China. Unquestionably, their translations rank among the very finest English versions of Chinese fiction from any period". [2] With such high evaluation, this translated version surely deserves much more attention and should be studied so as to see how the values implied in the source text are delivered and promoted in the target eco-environment.

Since the Republic of China, Sanyan has attracted the attention of an increasing number of scholars both at home and abroad, who have conducted relevant researches from the perspective of literature, sociology, comparative literature, and communication studies. The research covers the following areas such as the life, thoughts and writing of Feng Menglong, the contents, art forms, characters in his works, as well as the female and their views of love and marriage displayed in his works, etc. [3]. The translation studies of Sanyan mainly focus on the tracing of its various translated versions, comparative study between different translated versions, translation strategies and skills, translation style, and the dissemination of Sanyan overseas and so on. For instance, Wang Hualing and Tuyuanguo [3] "reviews the current status of translation studies concerning "Sanyan" from the perspective of history, digs out the reasons behind this phenomenon, and looks into the future trends". Lu Danjun [4] [5] collects and traces all the translated versions of Sanyan from bibliographical point of view. Yan Ming [6] introduces the background information of Shuhui Yang and Yunqin Yang, and the guiding translation thoughts and strategies in translating Sanyan. Li Xinting and Zhuang Qunying study the translators Zhang Xinqiang and Wang Jizhen and their translations of Sanyan [7] [8]. The dissemination of Sanyan in the foreign countries like Japan and Russia has also been studied [9] [10].

Compared with the researches on Sanyan and FengMenglong, fewer re- 
searches have been conducted on the translation of Sanyan, not to mention the translation produced by Shuhui Yang and Yunqin Yang. As the most complete translation of the 120 vernacular short novels in the collections, the related study on it is of great significance. Therefore, the current paper mainly studies the Yangs' translation of Sanyan from the perspective of Eco-Translatology.

\section{General Introduction to the Translations of Sanyan}

Like many Chinese classical masterpieces, Sanyan was also originally partially translated and introduced into the western regions by those envoys, businessmen and churchmen in China who have particular interest in Chinese culture. The earliest English translation of Sanyan can trace back to the 18th century when John Watts organized people to translate the French Description geographique, de I'Empire de la Chine et de la Tartarie Chinoise into English version The General History of China (later renamed as A Description of the Empire of China and Chinese Tartary), which only includes three selected stories from $\mathrm{Sa}$ nyan [5].

The translated versions of Sanyan in the early periods are diversified, but most of them are the translation of a single or several selected stories. For instance, Cyril Birch selected and translated six stories from Sanyan, namely, The Lady Who Was a Beggar, The Pearl-sewn Shirt, Wine and Dumplings, The Journey of the Corpse, The Canary Murders and The Fairy's Rescue. They were edited into Stories from a Ming Collection published by Indiana University Press. Yang Xianyi and Gladys Yang successively translated fifteen stories chosen from $\mathrm{Sa}$ nyan and published them in Chinese Literature, such as The Oil Vendor and the Courtesan, The Jade Worker and so on [5].

Until the 20th century, Stories Old and New. A Ming Dynasty Collection, Stories to Caution the World: A Ming Dynasty Collection Volume 2, Stories to Awaken the World: A Ming Dynasty Collection Volume 3 were successively published in Washington University Press in the year 2000, 2005 and 2009. It takes Shuhui Yang and Yunqin Yang fifteen years to finish the translations, and is the first complete translation of Sanyan by far. This version of translation later was collected into the Library of Chinese Classics and respectively published in Yuelu Publishing House in 2007, 2009 and 2011 [6].

By tracing the translation history of Sanyan, it can be easily found that the version by Shuhui and Yunqin Yang is the only one that maintains and reproduces the original structure in completeness. As evaluated by Robert E. Hegel, "their versions are eminently readable, accurate and lively; they have managed to hit just the right tone in their translations to convey simultaneously the fun of entertainment and the seriousness of FengMenglong's moral engagement with the social problems of the day" [2]. Though the two translators also emphasize in their paper the different trial techniques adopted in order to achieve loyalty to the linguistic style in the source text [11], it is never the only criterion that is taken into consideration by them, as translation is a complex activity involving 
the coordination of multi-components. Hence, analysis of their translation is conducted in the following part from the perspective of Eco-translatology.

\section{Analysis of Shuhui Yang and Yunqin Yang's Translation of Sanyan from the Perspective of Eco-Translatology}

Eco-translatology was first raised by Chinese scholar Hu Gengshen in 2001. It is a cross-disciplinary theory integrating Ecology and Translatology, so it can be understood as an ecological approach to translation studies or translation studies from an ecological perspective [12]. According to the Eco-translatology, the translator is put at the center of the whole translational eco-environment, which includes "the worlds of the source text and the source and target languages, the linguistic, cultural, and social aspects of translating, as well as the author, client, and readers" [13]. However, the translator is never dominating the whole translation process only by his own will. Instead, he will coordinate the relationship between various elements in the translational eco-system, trying to achieve a balance among the source text and writer, the target readers as well as the translator himself. Therefore, in this part, the translated version of Sanyan by Shuhui Yang and Yunqin Yang will be explored, mainly from the aspects of source text, target readers and translators.

\subsection{Loyalty to Source Text and Source Writer}

Faithfulness not only reflects on language itself but also on style, which is frequently not easy to achieve for translators due to the evident distinctions between Chinese and English. Different from the previous translators, the Yang not only translated the main body of each story in the vernacular short-story collections, but also "the storyteller's rhetoric, the verses, the prologue stories" as well as "the interlineal and marginal comments" in the original text which were often omitted in the existing translated works of Sanyan. [1] This clearly shows that the Yang try to be faithful to the source text and author in terms of the general structures and styles in order to spread the brilliant ancient cultural essence to the western countries in an authentic manner and let the target language readers have a direct appreciation of the vernacular short stories in China. According to the Yang, story-telling, as a symbol of huaben novels greatly promoted by FengMenglong, should be maintained in the translation, and meanwhile, the translation of verses and the prologue stories, as important components of Sanyan, are also of great significance. "The interlineal and marginal comments reflect the values of litterateurs in the 17th century and show us the essence of the book that deserves our appreciation, so these comments should also be translated" [6].

It can be found from the above that the Yang have laid great emphasis on maintaining loyal to the structural completeness of the source text, which, according to eco-translatology, is a significant component in the translational eco-environment. Such selection is made by the Yang mainly due to "the trans- 
lator's inner eco-system including the translator's cultural ideology, political stance, psychological traits and aesthetical value, etc." [14] Just as argued by the two translators themselves, "the true nature of the collection can only be appreciated when reading all of the stories in their original order" [2]. Therefore, in order to deliver this "true nature" to the target readers, the Yang choose to translate Sanyan in their "original order".

\subsection{Catering to the Target Readers' Expectation}

As Shuhui Yang and Yunqin Yang regard 'transplanting' as a shortcut to be more faithful to the original text in style on the one hand, and a significant means to cater to the target readers' expectations on the other hand. That is, they use similar language expressions in the classical literature works in America or the European countries between the 17th and 19th century to best reflect the classical style of the original work Sanyan. Meanwhile, such expressions are no strange to the target readers so they can be easily understood and accepted by the readers [11]. For instance, there is a sentence in the third story in the source text of Stories to Awaken the World, “若把西湖比西子, 浓妆淡抹总相宜”, which is translated as "Shall I compare the West Lake to Xishi,/Just as Charming with makeup heavy or light?". This seems obvious that they get this inspiration from Shakespeare's Sonnet, "Shall I compare thee to a summer's day". The translation method of "borrowing" or "transplanting" can help the target readers to better accept the translation. Other examples are listed below to show the translators have done their best to enhance the readability of the translation for the sake of target readers while maintaining the original flavor and disseminating the Chinese cultures abroad.

\section{Example 1.}

ST: 善助英雄壮胆, 能添锦绣诗肠。神仙造下解愁方, 雪月风花玩赏。[1] p. 424

TT: I help mighty heroes gain more courage, I lend gifted poets more inspiration.

The gods made the brew to dispel sorrows, To enjoy better the moon, snow, winds and flowers. [1] p. 425

\section{Example 2.}

ST: 好色能生疾病, 贪杯总是清狂。八仙醉倒紫云乡, 不羡公侯卿相。[1] p. 424

TT: Lust leads to illness, Wine only turns you heady.

The Eight Immortals, tipsy in Purple Cloud Land, Envy not the princes and the dukes. [1] p. 425

In the above two examples, “神仙” and “八仙” are respectively translated into "the gods" and "the Eight Immortals". Both "gods" and "immortals" are familiar to the westerners, so such translation can be easily accepted by the target readers. What is worth exploring is the possible reasons of such choice of words. In Chinese, Shen (神) and Xian (仙) are always used together, but they bear different 
connotations. Xian usually refers to those "practicing asceticism and alchemy to obtain 'Dao' so as to become the extraordinary person who is immortal and is at liberty to enjoy oneself", while Shen indicates "supernatural existence with the mystical power to dominate the world”. [15] Therefore, in Example 1, “神仙” here is used merely as a general term indicating those with mystical and supernatural power, so the Yang choose the general word "gods" as its corresponding translation. However, “八仙” in Example 2 is a cultural-loaded term in China with specific connotation, indicating the eight immortals in Taoist folklores, namely, Li Tieguai, zhongLiquan, LanCaihe, Zhang Guolao, He Xiangu, Lü Dongbin, Han Xiangzi and Cao Guojiu. Thus, the Yang capitalize "eight immortals", making it a special term, and meanwhile, add an endnote to further inform the readers about the alien cultures, which goes "These are eight immortals (seven males and one female) in popular Daoist legends".

The above examples well display that the Yang have also taken the target readers into consideration beside the source text and writer in their translating process. Either domestication by borrowing expressions from the existing European or American literature, or foreignization by literally translating with endnotes, both strategies are adopted by the Yang to meet the expectations of the target readers.

\subsection{Translator Centeredness}

In the translational eco-environment, the translator is regarded to be the center and plays a guiding and decisive function in the translation process. Specifically speaking, the translator first has to adapt to the translational eco-environment such as the language, culture and society, and then make adaptive selection about the concrete translation problems. The Yang make their own adaptive selections by fully using the central position in the translational eco-system when translating the cultural-loaded expressions, because there is no set rules or regulations to translate such information. In translating such cultural-loaded expressions, they prefer endnote more than any other technique, and a simple reason is that endnote doesn't necessarily appear on the same page as the translated information, so readers of various levels may choose their own way to read the target text, to read the endnote or not. But endnote is not the only skill that they rely on. They just make flexible choices based on the translational eco-environment or how important the concerned culture is. The following examples can display the adaptive selections made by the Yang in translating culture-loaded terms.

Example 3.

ST: 内中单表江西南昌府进贤县, 有一人姓张名权, 祖上原是富家, 报充 了个粮长。[16] p. 1132

TT: Let me tell of one named Zhang Quan of Jinxian County, Nanchang Prefecture, Jiangxi. The Zhang family used to be rich and had therefore been put in charge of collecting farm tax in the form of grain and delivering it to government-assigned granaries. [16] p. 1133 


\section{Example 4.}

$\mathrm{ST}$ : 日月盈亏, 星辰失度, 为人岂无兴衰? 子房年幼, 逃难在徐丕, 伊尹 曾耕莘野, 子牙尝钓磻溪…… [1] p. 212

TT: The sun rises and sets, the moon waxes and wanes, And the stars shine and dim in their cycles.

How can human lives not have their ups and downs?

In their youth, Zhang Liang took refuge in Xiapi, ${ }^{1}$ Yi Yin plowed the fields of Youxin; ${ }^{2}$ Lü Wang fished by Panxi Creek. ${ }^{3}[1]$ p. 213

In Example 3, “粮长” is a special term originating from the Ming dynasty, so to make the readers understand this sentence, the translators choose to explain its concrete functions by adding "in charge of collecting farm tax in the form of grain and delivering it to government-assigned granaries". This brief interpretation of the term delicately adds the related historical information without any interruption of the reading. In Example 4, the excerpted part is composed of poetic lines with many names of Chinese historical figures, so the translators have to use transliteration when translating these names to maintain the original style and flavor of the source text. It's not advisable to add too much historical information within the translated text, and thus, concerned information are put at the end of this story as endnotes to inform the target language readers culturally. For instance, “子牙” is explained in the third endnote, which goes as follows, "Lü Wang-popularly known as Taigong Wang, Jiang Taigong, or Jiang Ziya-was a military strategist who did not rise to eminence until he was accosted by King Wen of the Zhou dynasty (ca. 1027-256 B.C.E.) while fishing by Panxi Creek, which flowed into the Wei River. He was already about eighty years old.” [1] p. 265

Generally speaking, if the culture-loaded term can be easily explained without long-line coverage, further information may simply be added in the translation. If more detailed cultural information has to be introduced to the readers, the translators may also use endnote skill.

\section{Conclusion}

When the translator has his own leading role and central position in the translational eco-environment, he can actively engage in translation activities through flexible strategies or skills, so as to make the translational eco-environment a harmonious, united and interdependent one [17]. By analyzing the Yang's translation of Sanyan, it's easy to find out that Shuhui Yang and Yunqin Yang have brought their "translator centeredness" into full play, not only being loyal to the source text by maintaining the structural completeness in the target text, but also catering to the expectations of the target readers by applying foreignization or domestication strategies. No Matter what strategy they adopt, or what skill they use, they can be regarded as active, dynamic and flexible selections from Shuhui and Yunqin Yang in order to "make modern English carry a classical tone, achieve maximum equivalence in style and form, and strike a balance 
between over-translation and under-translation by properly managing the problem as to where to add notes" [6]. Therefore, it can be seen that the Yang have achieved balance and harmony in translating Sanyan by coordinating the relationship among the source text and writer, the translator and the target language readers, which ensures that the Yang's translation can better survive in the translational eco-environment.

\section{Acknowledgements}

This paper is sponsored by American Studies Center of Southwest Jiaotong University (Project Number: ARC2018024; Project Name: Study on American Heritage Education).

\section{Conflicts of Interest}

The authors declare no conflicts of interest regarding the publication of this paper.

\section{References}

[1] Feng, M.L. (2009) Stories to Caution the World (S.H. Yang and Y.Q. Yang, Trans. Vol. 1). Yuelu Publishing House, Changsha.

[2] Feng, M.L. (2012) Stories to Awaken the World: A Ming Dynasty Collection. (S.H. Yangand Y.Q. Yang, Trans. Vol. 3). University of Washington Press, Seattle.

[3] Wang, H.L. and Tu, Y.G. (2017) On the History of Translation Studies of Sanyan. Journal of Hunan University of Science \& Technology (Social Science Edition), 20, 148-155.

[4] Lu, D.J. (2005) A Bibliographical Study of English Renditions of "San-yan" Story Titles. Library, 2, 103-106.

[5] Lu, D.J. (2005) A Comparative Study of English Translations of "San-yan". Seeker, 4, 163-166.

[6] Yan, M. (2013) Both the Inner Beauty and the Rebuilding Ability-Introduction to the First Complete English Translation of "Sanyan". Chinese Translators Journal, 34, 75-79.

[7] Li, X.T. and Zhuang, Q.Y. (2011) Overseas Chinese Sinologist Zhang Xincang and Translation of "San Yan". Journal of Huaibei Normal University (Philosophy and Social Sciences), 32, 154-156.

[8] Li, X.T. and Zhuang, Q.Y. (2011) Overseas Chinese Sinologist Wang Chi-chen and Translation of "San Yan". Journal of Dalian Maritime University (Social Science Edition), 10, 112-115.

[9] Liu, H.Y. (2004) "San Yan" in Japan. Journal of Bohai University (Social Science), 26, 6-8+18.

[10] Li, X.T. (2010) FengMenglong's “San Yan” in Russia. Journal of Hebei North University (Social Science Edition), 4, 4-6.

[11] Yang, S.H. and Yang, Y.Q. (2016) Exploring the "Shortcut" of Achieving Loyalty of Language Style-Taking English Translation of Sanyan as an Example. Chinese Translators Journal, 37, 101-105.

[12] Hu, G.S. (2008) Interpretation of Eco-Translatology. Chinese Translators Journal, 6, 
$11-15+92$

[13] Hu, G.S. (2003) Translation as Adaptation and Selection. Perspectives. Studies in Translatology, 11, 283-291. https://doi.org/10.1080/0907676X.2003.9961481

[14] Yue, Z.S. (2016) A Study on Construction of Eco-translation Criticism System. Ph.D. Thesis, Shanghai International Studies University, Shanghai.

[15] Xu, Z.H. (2011) Cultral Studies on Shuhui Yang and Yunqin Yang's Translation of Jingshi Tongyan. Master's Degree Thesis, Fujian Normal University, Fujian.

[16] Feng, M.L. (2011) Stories to Awaken the World (S.H. Yang and Y.Q. Yang, Trans. Vol. 3). Yuelu Publishing House, Changsha.

[17] Luo, D.J. and Sheng, J. (2017). Analysis of Hu Gengshen's Thoughts on "Eco-translatology" and Its Ontological Stance. Foreign Language Education \& Research, 5, 55-60. 